\title{
Socio Economic Impact of Lock down due to Covid-19
}

\author{
V. David Chella Baskar ${ }^{1 *}$, Tanuj Mishra ${ }^{1}$ and Usha Nandhini ${ }^{2}$ \\ ${ }^{1}$ Rani Lakshmi Bai Central Agricultural University, India \\ ${ }^{2}$ Karunya Institute of Technology and Science, India \\ *Corresponding author
}

K e y w o r d s
Covid-19,
Lockdown, Socio-
economic, Impact

\section{A B S T R A C T}

The outbreak of corona virus disease 2019 (COVID-19) has triggered a global health crisis that had a deep impact on the way we perceive our world and our everyday lives. The safety measure plays a major role in restraining this worldwide occurrence which has posted a serious threat to the whole mankind. This outbreak also affects different segments of the population and is specific detrimental to members of those social groups in the most vulnerable situations. The focus lies within this context of physical and social threat importance and high alertness were emphasized with the help of mass media tools to reach and teach every citizen globally about covid-19.This pandemic affects all segments of the population and is particularly detrimental to members of those social groups in the most vulnerable situations. Early evidence indicates that that the health and economic impacts of the virus are being borne disproportionately by poor people. For example, homeless people, because they may be unable to safely shelter in place, are highly exposed to the danger of the virus. People without access to running water, refugees, migrants, or displaced persons also stand to suffer disproportionately both from the pandemic and its aftermath whether due to restricted movement, fewer employment opportunities etc. with this background an attempt was taken to study the socio-impact of covid-19.

\section{Introduction}

The outbreak of corona virus disease 2019 (COVID-19) has triggered a global health crisis that had a deep impact on the way we perceive our world and our everyday lives. The safety measures play a major role in restraining this worldwide occurrence which has posted a serious threat to the whole mankind. This outbreak also affects different segments of the population and is specific detrimental to members of those social groups in the most vulnerable situations. The focus lies within this context of physical and social threat importance and high alertness were emphasized with the help of mass media tools to reach and teach every citizen globally about covid-19 (1,2). This pandemic affects all segments of the population and is particularly detrimental to members of those social groups in the most vulnerable situations. Early evidence indicates that that the health and economic impacts of the virus are being borne disproportionately by poor 
people $(5,6)$. For example, homeless people, because they may be unable to safely shelter in place, are highly exposed to the danger of the virus. People without access to running water, refugees, migrants, or displaced persons also stand to suffer disproportionately both from the pandemic and its aftermath whether due to restricted movement, fewer employment opportunities etc. with this background an attempt was taken to study the socio-impact of covid-19 $(3,4)$.

\section{Materials and Methods}

The present study was conducted an online opinion survey on Covid-19 to understand the socio economic impact of the corona virus (COVID-19) on Indian businesses, agriculture, education and livelihood of common man. The survey was undertaken among different kind of people belonging to different groups based on age, sex, education, residence, business, home quarantine, personal attitudes, social responsibility etc. The period of this survey was March 26-31, 2020. Convenient sampling methods were used for data collection and were represented as frequencies and percentages. A sum of 175 individuals has responded to the questionnaire designed towards the impact of lockdown due to the pandemic covid-19. Descriptive statistics were performed for all groups and subgroups based on the correct responses.

\section{Results and Discussion}

\section{Distribution of attributes}

\section{Age}

Age is the major factor affecting the activities of an individual during lockdown period. Our study explores that $11.4 \%$ of the sample respondents come under the age group of 20 23 , as they contribute in a active ambience for the upliftment of the society in their modest way. The younger generation was embedded with ideology and innovative thinking leading to formation of healthier surroundings. The carrying capacity of any information is well attained to the destination with the assistance of young volunteers (Fig. 1).

\section{Time spent at home on}

After all the world wars, the present world had witnessed such a massive lockdown, where the entire activities have been paralyzed and movements of commuters were totally restricted. Most of the respondent (26.3\%) was sensible in proceeding their official work from home and ensured a continuous work contributing to the services and development of the society. Other activities exhibited $23.7 \%$. As social networking added a crucial role in making their time most utilizable, it has contributed of $19.3 \%$. It is interesting to know that $9.6 \%$ of respondents were found to be engaged in cooking (Fig. 2).

\section{Reaction of people over Covid-19}

As this kind of pandemic is new to the current generation without any vaccination, $41.2 \%$ of the respondents have expressed fearful situation, followed by a panic situation $33.3 \%$ ). In this state of mind set, both the factors were in the clutches of commuters. Only $11.4 \%$ have reacted to the neutral state who were not interested in revealing their present mind behavior towards covid-19 (Fig. $3)$.

\section{Will lock down an essential tool?}

The Indian governmental policies, especially Digital India, play a major role and became the panacea for some most of the vulnerable sectors to face this crisis. The long term vision on Digital India was well accomplished and laid a strong foundation for upcoming 
era. Majority of the respondent expressed that lock down is essential tool (92 per cent) to break down the chain of pandemic covid-19 spread as there no vaccine so far invented.
The only possible way to control this outburst is to strict follow up lock down measures until the complete control over the this pandemic virus (Fig. 4).

Fig.1 Age

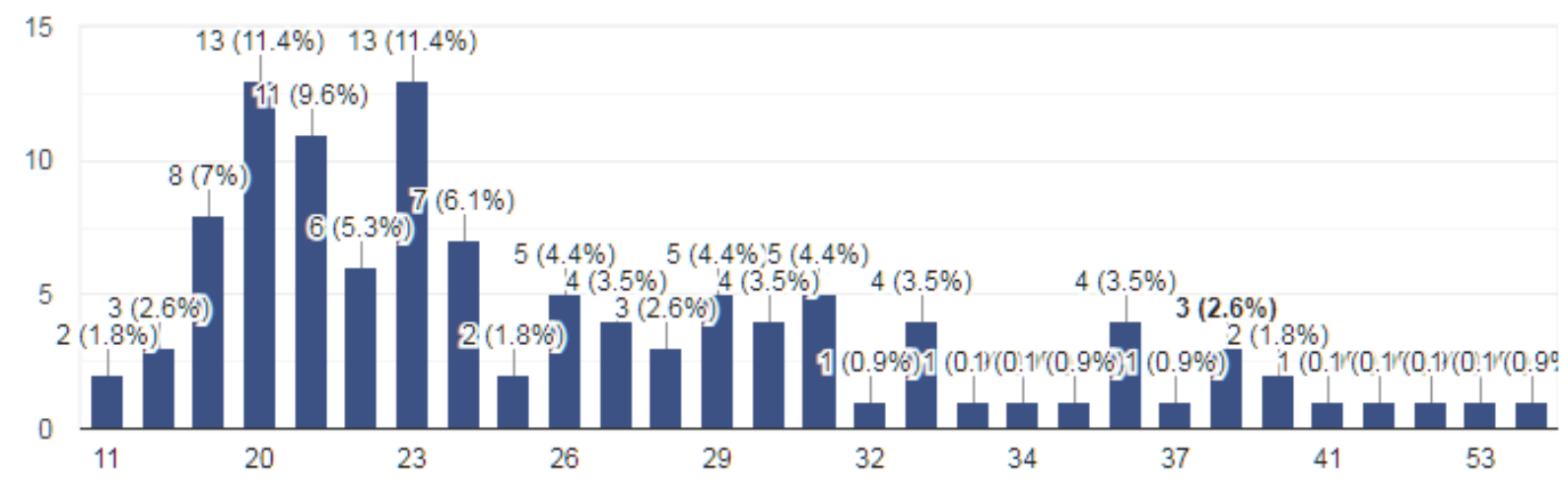

Fig.2 Time spent at home on
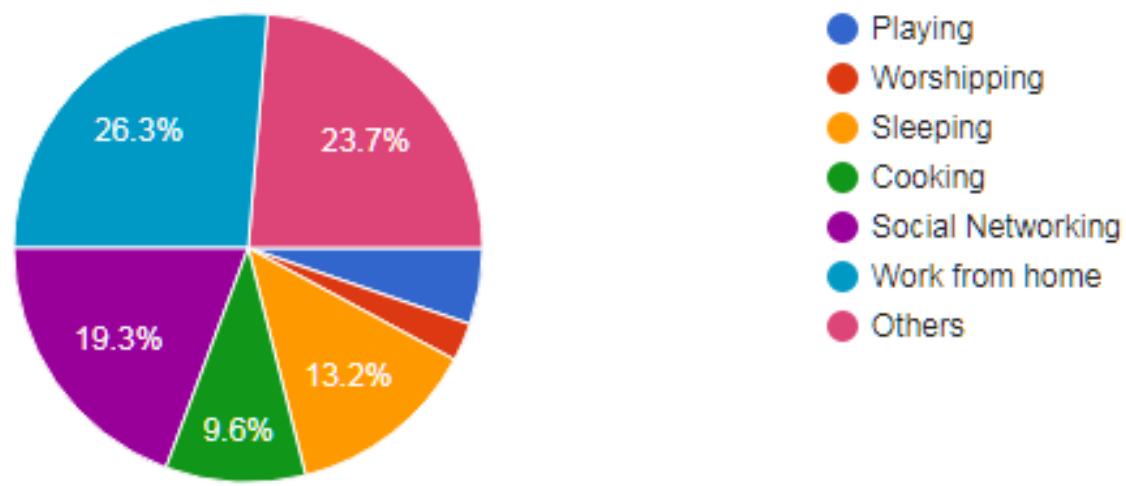

Fig.3 Reaction of people over Covid-19

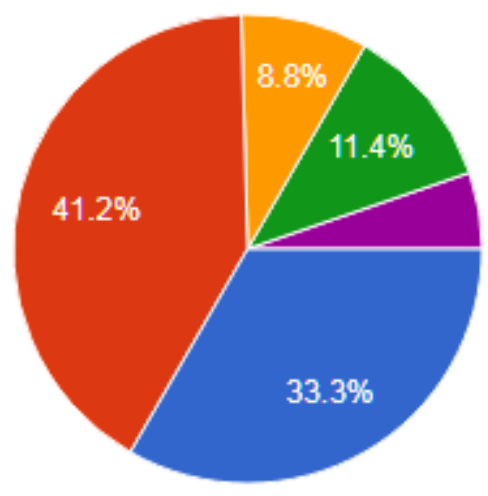

Panic

Fear

Peaceful

Neutral

Doesn't care 
Fig.4 Will lock down an essential tool?

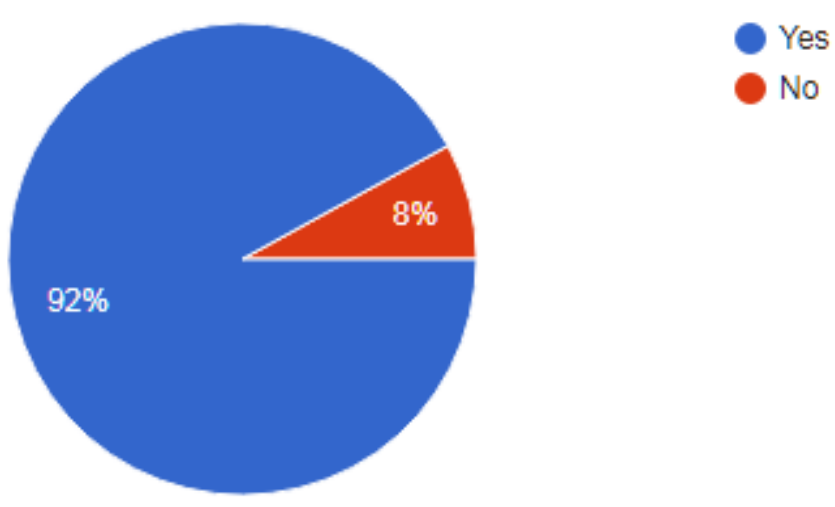

Fig.5 People aware of Covid-19

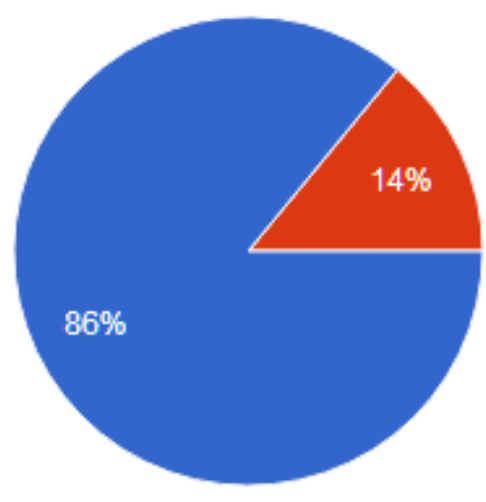

higher the awareness level. When it comes to health issues, people adhere to norms framed by government from time to time. The real issue is whether these efforts are being adequately supported and complemented by the Government with resources and with a clear- cut plan. Projecting a success cases on the basis of the aggregative statistical trends of infections alone, however, can only take us up to a point in answering the questions about the role of the policy.

It is concluded that this study is prevailing among the educated communities due to the nature of lockdown and hence the results depicted a positive impact from all groups of the respondents. Higher the education level

\section{References}

1. Anil Kumar et al., "Potential Impact of covid-19 on Indian economy” 2020. 
2. WHO Director-General's opening remarks at the media briefing on COVID19 - 11 March 2020. (2020). Accessed: Mar 19, 2020.

3. Modi PD, Kumar P, Solanki R, Modi J, Chandramani S, Gill N: Hand hygiene practices among Indian medical undergraduates: a questionnaire-based survey. Cureus. 2017, 9:e1463. Accessed: March 25, 2020:

4. Langade D, Modi PD, Sidhwa YF, et al., Burnout syndrome among medical practitioners across

5. India: a questionnaire-based survey. Cureus. 2016, 8(9)

6. https://www.undp.org/content/undp/en/ho me/librarypage/crisis-prevention-andrecovery/the-social-and-economicimpact-of-covid-19-in-asia-pacific.html

7. https://www.indiabriefing.com/news/social-economicimpact-covid-19-india-recoverypotential-20202.html/

\section{How to cite this article:}

David Chella Baskar, V., Tanuj Mishra and Usha Nandhini. 2020. Socio Economic Impact of Lock down due to Covid-19. Int.J.Curr.Microbiol.App.Sci. 9(06): 4210-4214. doi: https://doi.org/10.20546/ijcmas.2020.906.493 